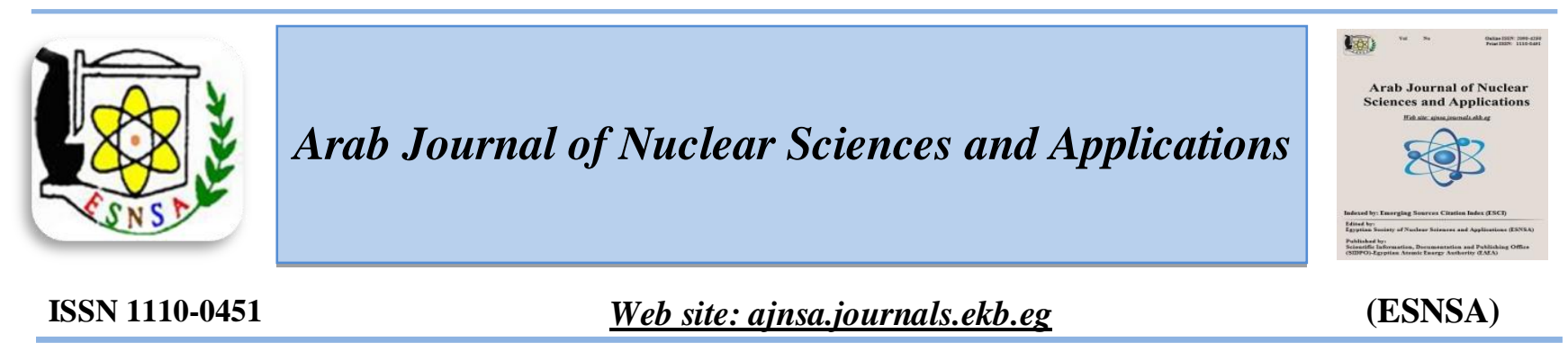

\title{
Extraction of Some Rare Earth Elements (La, Pr and Er) from Citrate Medium Using D2EHPA in kerosene
}

\author{
E.M. Abu Elgoud ${ }^{(1)}$, Z.H. Ismail ${ }^{(1)}$, Y.A. El-Nadi( ${ }^{(1)}$, S.M. Abdelwahab ${ }^{(2)}$, H.F. Aly ${ }^{(1)}$ \\ ${ }^{(1)}$ Hot Laboratories Center, Atomic Energy Authority, Post Code 13759, Egypt \\ ${ }^{(2)}$ Chemistry Department, Faculty of Science, Ain Shams University, Egypt
}

\begin{abstract}
Received $4^{\text {th }}$ April 2019 Extraction and possible separation of the rare earth elements, REEs, lanthanum (III), praseodymium Accepted $17^{\text {th }}$ April 2019 (III) and erbium (III) from citric acid solution using Di(2-ethylhexyl) phosphoric acid, D2EHPA, in kerosene were studied. The parameters affecting the extraction process were separately studied in order to achieve the maximum possible separation between the different REEs under investigation. It was found that from $1.0 \mathrm{~mol} / \mathrm{L}$ citric acid solution at $\mathrm{pH}=4.0$, the extraction is dependent mainly on the citric acid and D2EHPA concentration as well as temperature. From the experimental results and the main species in the aqueous phase, a proposed extraction equilibrium of the different metal ions was given. Conditional extraction constants for the proposed extraction equilibrium were calculated for the different elements, and found to verify the experimental results. The order of the conditional extraction constants follows the sequence, Er (III) $>$ La (III) $\geq \operatorname{Pr}$ (III). The thermodynamic functions associated with the extraction reaction were evaluated and discussed. Feasibility of separation of Er(III) from La (III), and Pr (III) obtained was given in terms of the separation factors between different elements at different extraction conditions.
\end{abstract}

Keywords: Extraction; REEs; Citric acid; D2EHPA; Separation.

\section{Introduction}

Rare Earth elements (REEs) are a group of metals which consists of yttrium and 14 elements of the lanthanides in addition to scandium. The unsaturated $4 \mathrm{f}$ electronic structure of lanthanides gives the special properties of the REEs in many fields such as luminescence, magnetism, catalysis, and electronics. REEs have been used in glass polishing, phosphors, batteries, magnets and thermal neutron absorbents. The relatively new applications in the electronics and other industries have resulted to an increased demand for lanthanide materials [1,2]. REEs are generally obtained from minerals as a mixture from which they are separated in groups or as individual elements at varying levels of purity, depending on the use. For the separation purposes, liquid-liquid extraction is one of the main techniques used in industry.

The rare earth elements are extracted and separated from different acid solutions by using different types of extractants including acidic, basic and neutral ones [3-8]. Acidic organophosphorus extractants, such as $\operatorname{Di}(2$-ethylhexyl) phosphoric acid (D2EHPA), were used for the separation of the REEs using solvent extraction technique $[9,10]$. D2EHPA is one of the acidic extractants which are utilized extensively in the field of $f-$ elements separation. In addition, it has extensive applications in the separation of lanthanides from fission products [11-13].

Solvent extraction of REEs by D2EHPA from various acidic media like hydrochloric, sulfuric

Corresponding author: esnsa group@yahoo.com

DOI: 10.21608/ajnsa.2019.11545.1202

(C) Scientific Information, Documentation and Publishing Office (SIDPO)-EAEA 
and nitric acid solutions is reported [14-17]. It was found that the extraction of REEs with D2EHPA from hydrochloric acid and sulfuric acid media is the same while it is lower from nitric acid solution. Many efforts were devoted to find out some new extraction systems superior to the current saponified D2EHPA system. Recently, much efforts have been devoted to explore some new extraction systems superior to the current D2EHPA-mineral acid system. Among these, which is more effective includes the introduction of complexing agents into the aqueous phase [1826]. As early as 1968, Weaver and Kappelmann [27] used a mixture of citric acid and aminopolyacetic acids for preferential separation of lanthanides from actinides without modeling of the extraction mechanism. Toshihiko Ohnuki et al. [28] investigated the chemical states change of lanthanides and actinides in the presence of citric acid solutions. The value of distribution ratio in the presence of citric acid was lower than that in the absence of citric acid, reflecting the formation of Ln(III)-citrate complexes. The results indicated that the presence of organic acids affects the chemical state of lanthanides and actinides. Suneesh et al. [29] investigated the separation between lanthanides and actinides from a mixture of $0.1 \mathrm{M}$ citric acid and nitric acid solution. Yin et al. [30-32] studied the extraction and separation of light rare earth elements using two complexing extraction system based on lactic acid and citric acid with D2EHPA, and the results showed that it could not only improve the extraction efficiency, but also increases the selectivity among some adjacent rare earth elements.

In a previous work, the leaching efficiency of 1.0 $\mathrm{mol} / \mathrm{L}$ citric acid solution for different lanthanides present in phosphogypsum fertilizer (PGF), was found to be in the order $\operatorname{Er}(89.4 \%)>\mathrm{La}(81.9 \%)>$ $\operatorname{Pr}(72.0 \%)$ [33]. Therefore, the main objective of the present work is directed to study the effects of D2EHPA concentration, $\mathrm{pH}$, contact time, temperature, and phase ratio on the extraction and separation of lanthanum(III), erbium(III) and prasodymium(III) ions from $1.0 \mathrm{~mol} / \mathrm{L}$ citric acid medium. In addition, extraction equilibrium for different investigated ions was proposed and a conditional extraction constant was calculated for each of the studied metal ions and verified the solvent extraction results.

\section{Experimental}

Materials

Stock solutions of $\mathrm{La}(\mathrm{III}), \operatorname{Pr}(\mathrm{III})$ and $\operatorname{Er}(\mathrm{III})$ (1.0 $\mathrm{g} / \mathrm{L}$ ) were prepared by dissolving a known amount of the metal oxides produced by Aldrich in a minimum amount of concentrated nitric acid. The solution was evaporated to near dryness, washed with double distilled water (d.d.w) until it became almost free from nitrate ions, then completed to one liter with d.d.w. Required concentrations of the investigated metal ions were prepared from the stock solutions by dilution. Citric acid is a weak organic acid that has the chemical formula $\mathrm{C}_{6} \mathrm{H}_{8} \mathrm{O}_{7}$. The extractant D2EHPA which was purchased from Aldrich is a viscous liquid with the formula $\left(\mathrm{C}_{8} \mathrm{H}_{17} \mathrm{O}\right)_{2} \mathrm{PO}_{2} \mathrm{H}$, a specific gravity of $1.038 \mathrm{~g} / \mathrm{cm}^{3}$ and molecular weight of $322.4 \mathrm{~g} / \mathrm{mol}$. It is insoluble in water but exceedingly soluble in organic solvents. The odorless non-aromatic kerosene was used as a diluent for the extractant and obtained from Misr Petroleum Company, Egypt. The total lanthanide concentrations in the studied samples were determined spectrophotometrically by the Arsenazo III method [34]. Individual element in their mixture was determined by ICP-OES. All other reagents were used as supplied without further purification.

\section{Extraction Procedure}

Solvent extraction was performed by shaking equal volumes $(5.0 \mathrm{ml})$, unless otherwise given, of aqueous and organic phases until equilibrium in glass tubes using a water-thermostat shaker of the type G.F.L 1083, Germany at $298 \pm 1$ K. After extraction, the aqueous and organic phases were separated completely using a centrifuge. The concentration of rare earth ions in the aqueous phase was determined spectrophotometrically using a UV-visible spectrophotometer model Shimadzu, UV-160A, Japan. The concentration of the rare earth ions in the organic phase was obtained by mass balance. The distribution coefficient (D), extraction efficiency (\%E) and separation factor (SF) were calculated from the following equations:

$D=\frac{[C]_{t}-[C]_{a}}{[C]_{a}}$
$\% E=\frac{100 D}{D+\left(V_{a q} / V_{\text {org }}\right)}$
$S F=\frac{D_{1}}{D_{2}}$ 
Where, $[\mathrm{C}]_{\mathrm{t}}$ is the original metal concentration in the aqueous phase before extraction, $[\mathrm{C}]_{\mathrm{a}}$ is the metal concentration in the aqueous phase after extraction, $V_{\text {aq }}$ is the volume of the aqueous solution and $\mathrm{V}_{\text {org }}$ is the volume of the organic solution. $\mathrm{D}_{1}$ and $\mathrm{D}_{2}$ denote the distribution ratios of two individual rare earth metal ions.

\section{Results and Discussion}

\section{Factors affecting the extraction}

The different factors affecting the extraction investigated are the effect of shaking time, the $\mathrm{pH}$ of the aqueous solution, D2EHPA molar concentration, phase ratio (volume of aqueous (A) over volume of organic phase $(\mathrm{O})$ ) and citric acid molar concentration.

\section{Effect of shaking time}

The extraction of $\operatorname{Er}($ III), $\mathrm{La}$ (III) and $\operatorname{Pr}$ (III) from $1.0 \mathrm{~mol} / \mathrm{L}$ citric acid solution at $\mathrm{pH}=4.0$ was carried out by shaking equal amounts of the aqueous and organic phases of $0.02 \mathrm{~mol} / \mathrm{L}$ D2EHPA for different time intervals ranging from 5.0 to $60.0 \mathrm{~min}$ at $25^{\circ} \mathrm{C}$, Figure (1). It is clear that for $\mathrm{Er}(\mathrm{III})$, as the time increased from 5.0 to 10.0 $\mathrm{min}$, the extraction efficiency $(\% \mathrm{E})$ increased from $80.6 \%$ to $93.1 \%$, and remained almost constant up to $60.0 \mathrm{~min}$. In case of other metal ions, as the shaking time increased from $5.0 \%$ to $10.0 \% \mathrm{~min}$, the $\% \mathrm{E}$ increased from $10.5 \%$ to $10.8 \%$ and from $8.2 \%$ to $9.6 \%$ for $\mathrm{La}(\mathrm{III})$ and $\mathrm{Pr}$ (III), respectively. This is followed by a slight decrease with further increase of shaking time due to possible back extraction of metal ions. Therefore, the used shaking time for extraction of the studied metal ions was fixed at $10.0 \mathrm{~min}$.

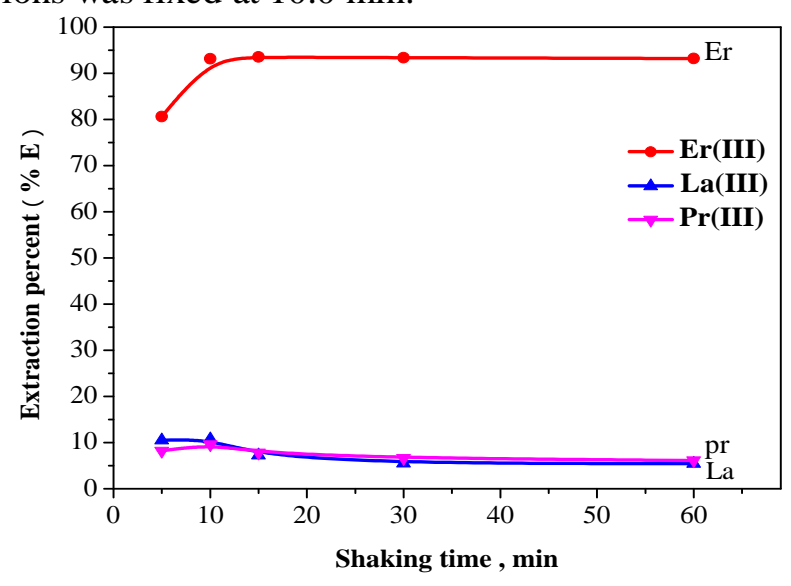

Figure (1): Effect of shaking time on the extraction of $\operatorname{Er}(\mathrm{III}), \mathrm{La}(\mathrm{III})$ and $\operatorname{Pr}(\mathrm{III})(500 \mathrm{mg} / \mathrm{L}$ each) from 1.0 $\mathrm{mol} / \mathrm{L}$ citric acid solution using $0.02 \mathrm{~mol} / \mathrm{L}$ D2EHPA in kerosene at $\mathrm{pH}=4.0, \mathrm{~A} / \mathrm{O}=1.0$ and $25^{\circ} \mathrm{C}$.

\section{Effect of $p H$}

The influence of $\mathrm{pH}$ variation on the extraction of the investigated metal ions in $1.0 \mathrm{~mol} / \mathrm{L}$ citric acid was carried out and presented in Figure (2). The results indicated that for $\mathrm{Er}(\mathrm{III})$, as the $\mathrm{pH}$ increased from 1.0 to 4.0 , the $\% \mathrm{E}$ increased from $89.4 \%$ to $93.1 \%$. In case of other metal ions, as the $\mathrm{pH}$ increased from 1.0 to 4.0 , the $\% \mathrm{E}$ increased from around $0.01 \%$ to $10.7 \%$ and from $1.9 \%$ to $10.7 \%$ for $\mathrm{La}(\mathrm{III})$ and $\mathrm{Pr}(\mathrm{III})$, alternatively. The increase in the $\mathrm{pH}$ values up to $\mathrm{pH} 5.0$ had a slight decrease of the $\% \mathrm{E}$ at $\mathrm{pH}$ 5.0. This decrease can be related to the possible formation of less extracted hydrolyzed metal ions. Therefore, $\mathrm{pH}=4.0$ was used as the $\mathrm{pH}$ value for further extraction experiments of the investigated metal ions from $1.0 \mathrm{~mol} / \mathrm{L}$ citric acid solution.

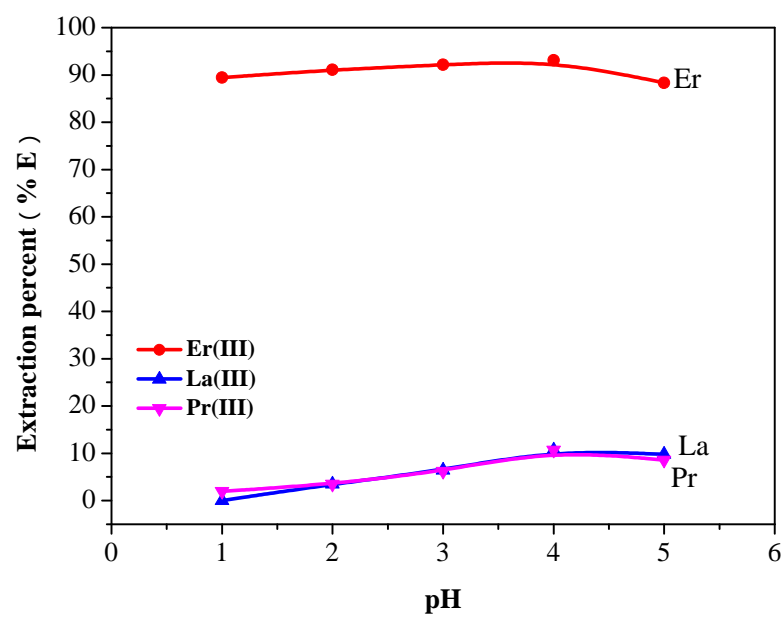

Figure 2: Effect of pH on the extraction of $\mathrm{Er}$ (III), La(III) and $\operatorname{Pr}(\mathrm{III})$ from $1.0 \mathrm{~mol} / \mathrm{L}$ citric acid solution using 0.02 mol/L D2EHPA in kerosene at $\mathrm{A} / \mathrm{O}=1.0$ and $25^{\circ} \mathrm{C}$.

\section{Effect of D2EHPA concentration}

The effect of varying D2EHPA concentration in kerosene in the ranges $0.005-0.08 \mathrm{~mol} / \mathrm{L}$ on the extraction of $0.5 \mathrm{~g} / \mathrm{L} \mathrm{Er}$ (III), from $1.0 \mathrm{~mol} / \mathrm{L}$ citric acid medium was studied. In case of $\mathrm{La}(\mathrm{III})$ and $\operatorname{Pr}(\mathrm{III})$ the change of D2EHPA concentration was within the range $0.02-0.08 \mathrm{~mol} / \mathrm{L}$. The obtained results are given in Figure (3). It is clear that the extraction percent increased with the increase in concentration of D2EHPA. Due to that the rare earth ions preferably form extracted complex with D2EHPA. However, $0.02 \mathrm{~mol} / \mathrm{L}$ D2EHPA was used to enable better separation of $\operatorname{Er}($ III) from other investigated metal ions. 


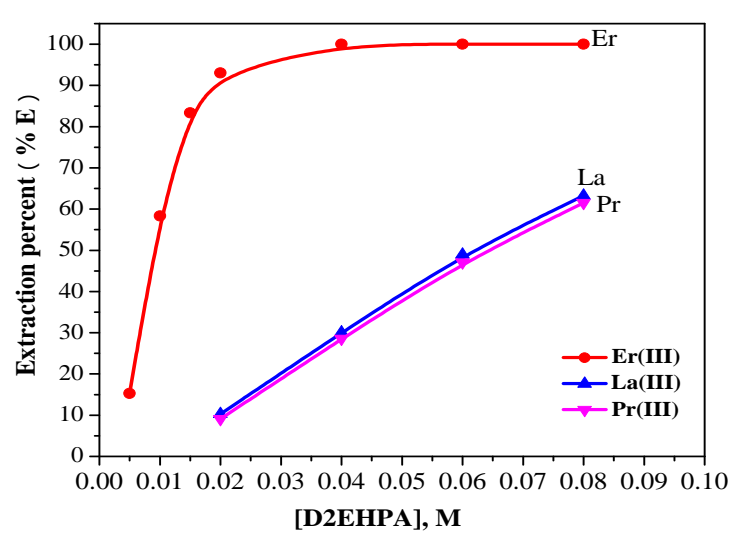

Figure (3): Effect of D2EHPA concentration on the extraction of $\operatorname{Er}(\mathrm{III}), \mathrm{La}(\mathrm{III})$ and $\operatorname{Pr}(\mathrm{III})$ from $1.0 \mathrm{~mol} / \mathrm{L}$ citric acid solution at $\mathrm{pH}=4, \mathrm{~A} / \mathrm{O}=1.0$ and $25^{\circ} \mathrm{C}$

\section{Effect of phase ratio}

The effect of contacting the various volume ratios of aqueous to organic phase on the extraction process was investigated and the results are shown in Figure (4). For $\operatorname{Er}(\mathrm{III})$, as the phase ratio increased from $1: 1$ to $1: 6$, the extraction efficiency (\%) decreased from $93.5 \%$ to $12.5 \%$. In case of $\mathrm{La}(\mathrm{III})$ and $\operatorname{Pr}(\mathrm{III})$, as the phase ratio increased from $1: 1$ to $1: 4$, the $\% \mathrm{E}$ decreased from $10.90 \%$ to $1.48 \%$ and from $10.01 \%$ to $1.65 \%$ for the two metal ions, respectively. This is due to the saturation of the D2EHPA.Therefore, the phase ratio of 1:1 was selected for the extraction experiments.

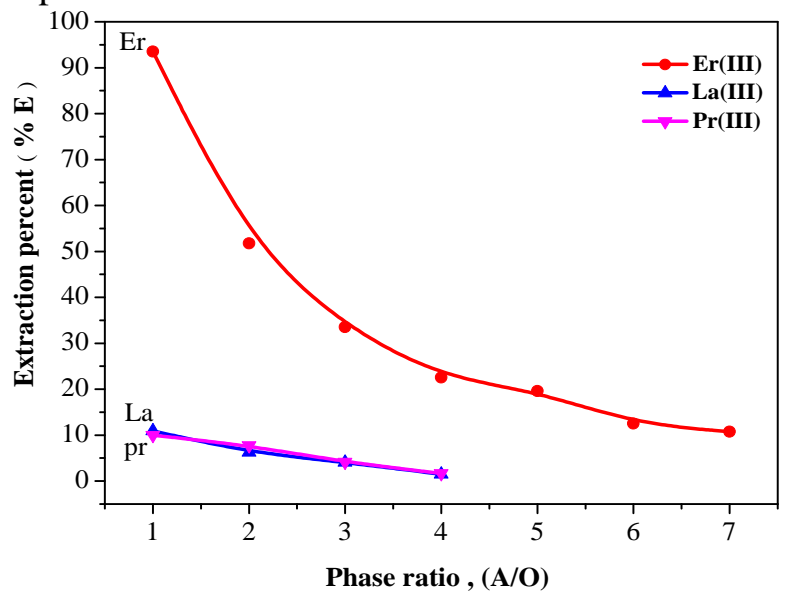

Figure (4): Effect of phase ratio on the extraction of Er(III), La(III) and Pr(III) from $1.0 \mathrm{~mol} / \mathrm{L}$ citric acid solution using $0.02 \mathrm{~mol} / \mathrm{L}$ D2EHPA in kerosene at $\mathrm{pH}=4.0$ and $25^{\circ} \mathrm{C}$.

\section{Effect of citric acid concentration}

The influence of citric acid molar concentration on the extraction of $\operatorname{Er}(\mathrm{III}), \mathrm{La}(\mathrm{III})$ and $\operatorname{Pr}(\mathrm{III})(0.5$ $\mathrm{g} / \mathrm{L}$ each) was studied in the citric acid concentration range $0.0-1.5 \mathrm{~mol} / \mathrm{L}$ using 0.02
mol/L D2EHPA in kerosene. The obtained results indicated that, as the citric acid concentration increases the extraction of metals decreases, Figure (5). The decrease can be related to the possible formation of less extractable metal ions citrate complexes in the aqueous phase.

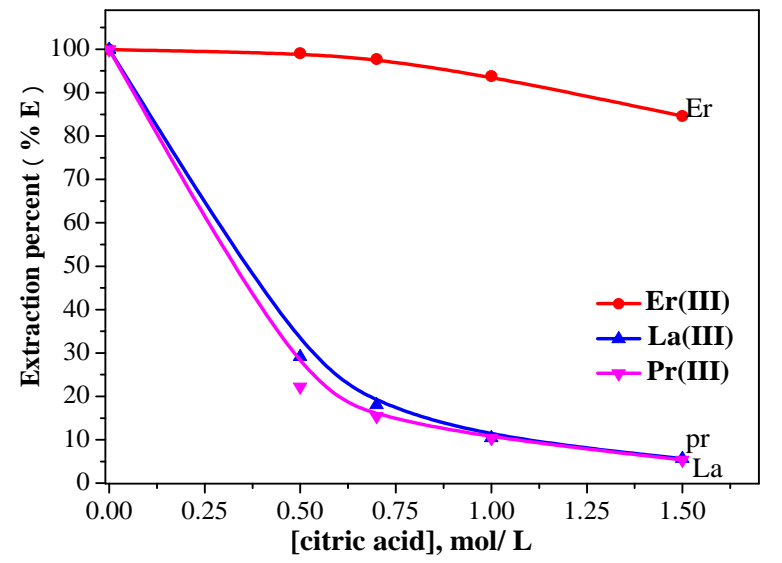

Figure (5): Effect of citric acid concentration on the extraction of $\operatorname{Er}(\mathrm{III}), \mathrm{La}(\mathrm{III})$ and $\operatorname{Pr}(\mathrm{III})$ using $0.02 \mathrm{~mol} / \mathrm{L}$ D2EHPA in kerosene at $\mathrm{pH}=4, \mathrm{O}: \mathrm{A}=1.0$ and $\mathrm{T}=25^{\circ} \mathrm{C}$.

\section{Modeling of the extraction equilibrium}

The aforementioned results indicated that the extraction of the investigated lanthanide metal ions from $1.0 \mathrm{~mol} / \mathrm{L}$ citric acid at $\mathrm{pH} 4.0$ solution increased by the increase of D2EHPA molar concentration and decreased by the increase of citric acid molar concentration. Further, due to the buffering effect of citric acid, the $\mathrm{pH}$ of citric acid solution has limited effect on the extraction for the metal ions investigated. This behavior can be modeled based on the reaction between the main metal cationic ion species at $\mathrm{pH} 4.0, \mathrm{Ln}^{3+}$, and the main anionic species of citric acid at the same $\mathrm{pH}$. In this concern, citric acid $\left(\mathrm{H}_{3} \mathrm{Cit}\right)$ is a tribasic acid with $\mathrm{pK}_{\mathrm{a} 1}=3.13, \mathrm{pK}_{\mathrm{a} 2}=4.76$ and $\mathrm{pK}_{\mathrm{a} 3}=6.40$ at $25^{\circ} \mathrm{C}$ [35]. According to Medusa program (www.kemi.kth.se/medusa), the speciation diagram for $1.0 \mathrm{~mol} / \mathrm{L}$ citric acid as function of $\mathrm{pH}$ is given in Figure (6) [36]. From this figure, more than $77.0 \%$ in the citric acid solution is present as $\left[\mathrm{H}_{2} \mathrm{Cit}\right]^{-}$at $\mathrm{pH}$ 4.0. Therefore, it is expected that this species represents the main anionic species responsible for complex formation with the different cationic lanthanide ions investigated. In aqueous solution at $\mathrm{pH} 4.0, \mathrm{La}(\mathrm{III}), \operatorname{Pr}(\mathrm{III})$, and $\mathrm{Er}(\mathrm{III})$ are present mainly in the free cationic form, [37]. Therefore, we can assume that in 1.0 $\mathrm{mol} / \mathrm{L}$ citric acid solution at $\mathrm{pH} 4.0$, interaction of $\left[\mathrm{H}_{2} \mathrm{Cit}\right]^{-}$with different trivalent ions $\left(\mathrm{Ln}^{3+}\right)$ can 
form complexes of the type $\left[\mathrm{Ln}\left(\mathrm{H}_{2} \mathrm{Cit}\right)_{3}\right]$ in solution.

Providing that D2EHPA is a dimer in kerosene [17], and extract cationic species in the organic phase, we can assume that the extraction of the former species will follow the general extraction equilibrium for trivalent lanthanides.

$$
\begin{aligned}
& \operatorname{Ln}\left(\mathrm{H}_{2} \mathrm{Cit}\right)_{3}+n(\mathrm{HA})_{2 \mathrm{org}} \rightleftarrows \\
& {\left[\mathrm{Ln}\left(\mathrm{H}_{2} \mathrm{Cit}\right)_{3-n} \cdot n \mathrm{~A} \cdot(\mathrm{HA})_{2}\right]_{\text {org }}+n \mathrm{H}_{3} \mathrm{Cit}}
\end{aligned}
$$

Where (HA) $)_{2}$ denotes D2EHPA in dimer form.

The conditional extraction constant, $\mathrm{K}_{\mathrm{C} \text {.ex }}$, at 1.0 $\mathrm{mol} / \mathrm{L}$ citric acid and $\mathrm{pH} 4.0$, is given by the following relation;

$$
\mathrm{K}_{\mathrm{C} . \mathrm{ex}}=\frac{\left[\operatorname{Ln}\left(\mathrm{H}_{2} \mathrm{Cit}\right)_{3-n} \cdot n \mathrm{~A} \cdot(\mathrm{HA})_{2}\right]_{o r g}\left[\mathrm{H}_{3} \mathrm{Cit}\right]^{n}}{\left[\mathrm{Ln}\left(\mathrm{H}_{2} \mathrm{Cit}\right)_{3}\right]_{a q}\left[(\mathrm{HA})_{2}\right]^{\mathrm{n}}}
$$

since the distribution ratio is given by;

$$
\mathrm{D}=\frac{\left[\mathrm{Ln}\left(\mathrm{H}_{2} \mathrm{Cit}\right)_{3-\mathrm{n}} \cdot \mathrm{nA}(\mathrm{HA})_{2}\right]_{\mathrm{org}}}{\left[\mathrm{Ln}\left(\mathrm{H}_{2} \mathrm{Cit}\right)_{3}\right]_{a q}}
$$

The conditional extraction constant, $\mathrm{K}_{\mathrm{C} . \mathrm{ex}}, 1.0$ $\mathrm{mol} / \mathrm{L}$ citric acid at $\mathrm{pH} 4.0$, is given as:

$$
\mathrm{K}_{\text {C.ex }}=\frac{\mathrm{D}\left[\mathrm{H}_{3} \mathrm{Cit}\right]^{\mathrm{n}}}{\left[(\mathrm{HA})_{2}\right]^{\mathrm{n}}}
$$

After linearization and arrangement,

$\log \mathrm{D}=\log \mathrm{K}_{\mathrm{C} . \mathrm{ex}}+\mathrm{nLog}\left[(\mathrm{HA})_{2}\right]-\mathrm{nLog}\left[\mathrm{H}_{3} \mathrm{Cit}\right]$

Therefore, it is expected that the relation between $\log \mathrm{D}$ against $\log (\mathrm{HA})_{2}$ will give a linear relation with positive slope equals to (n) and the slope of $\log \mathrm{D}$ against $\log \left(\mathrm{H}_{3} \mathrm{Cit}\right)$ will give a linear relation with negative slope of (n). It is to be mentioned again that the effect of hydrogen ion concentration is neglected due to the slight dependency of hydrogen ion due to the buffering action of the high concentrations of citric acid.

The log-log plot between the D2EHPA concentrations and the corresponding distribution ratios, Figure(7), gave linear relations with positive slopes of 3.0, 2.0 and 2.0 for $\mathrm{Er}(\mathrm{III}), \mathrm{La}$ (III) and $\operatorname{Pr}(\mathrm{III})$, respectively. This indicates that two dimers are involved in the extracted species for La(III) and $\operatorname{Pr}(\mathrm{III})$ except in case of $\operatorname{Er}(\mathrm{III})$ extraction where three dimers participates in the extracted metal species. On the other hand, a plot between $\log \mathrm{D}$ against the citric acid concentrations gives linear relations, Figure (8). The slopes of these lines were found to be $-3.0,-2.0$ and -2.0 for $\mathrm{Er}(\mathrm{III}), \mathrm{La}(\mathrm{III})$ and $\operatorname{Pr}(\mathrm{III})$, respectively. This indicates that two moles of citric acid is released in the aqueous medium during the extraction of $\mathrm{La}$ (III) and $\operatorname{Pr}$ (III) while in case of $\operatorname{Er}(\mathrm{III})$ three moles of citric acid are released in the aqueous medium during the extraction. These results support the general equilibrium given in equation (4). Subsequently, the proposed main trivalent Ln extracted cationic species in the organic phase from $1.0 \mathrm{~mol} / \mathrm{L}$ citric acid solution at $\mathrm{pH} 4.0$ are of the types $\left[\mathrm{La}\left(\mathrm{H}_{2} \mathrm{Cit}\right)\right]^{+},\left[\mathrm{Pr}\left(\mathrm{H}_{2} \mathrm{Cit}\right)\right]^{+}$and $\mathrm{Er}^{3+}$ in the organic phase. 


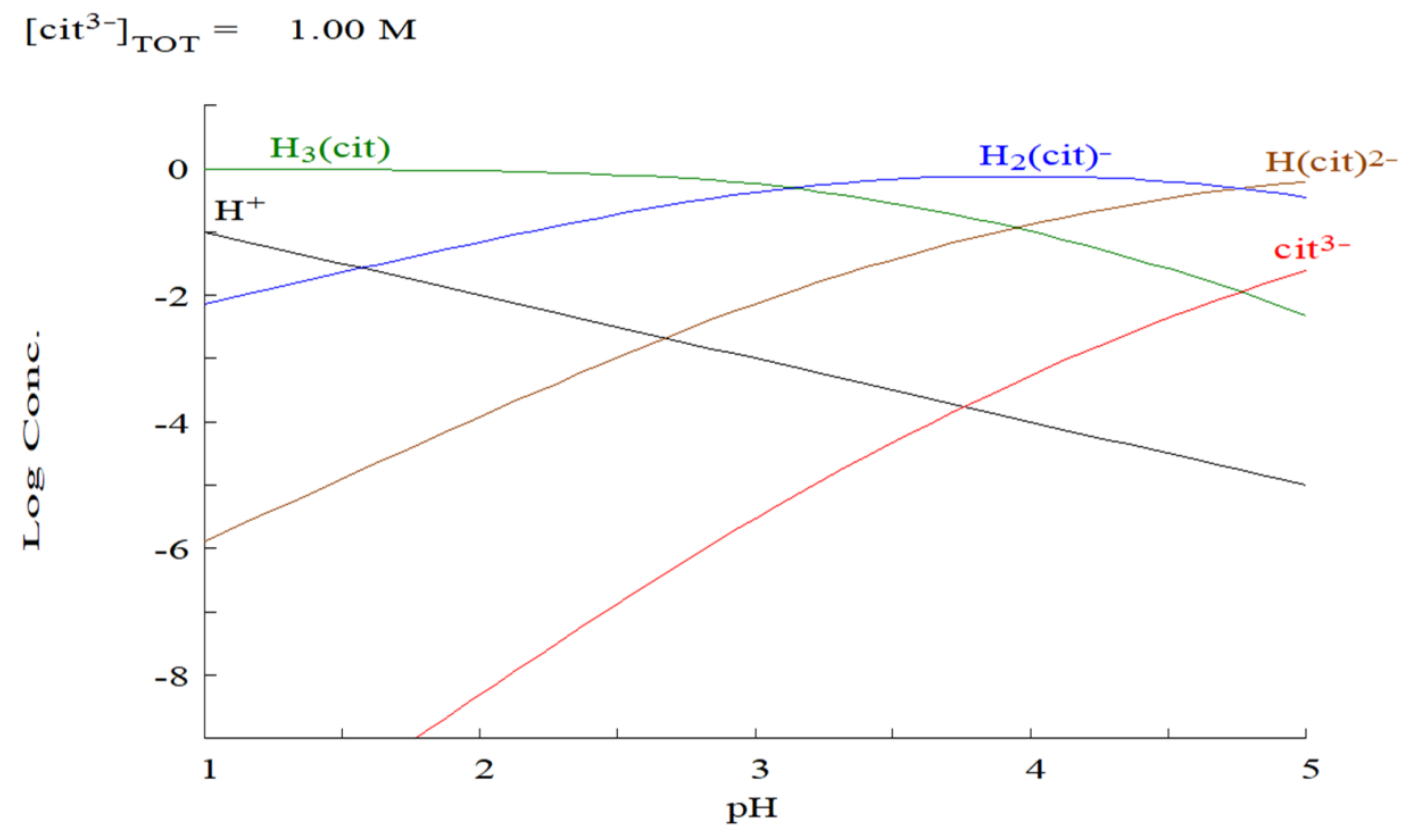

Figure (6): Equilibrium diagram of $1.0 \mathrm{~mol} / \mathrm{L}$ citric acid in $\mathrm{pH}$ range 1.0 - 5.0.

(www.kemi.kth.se/medusa )

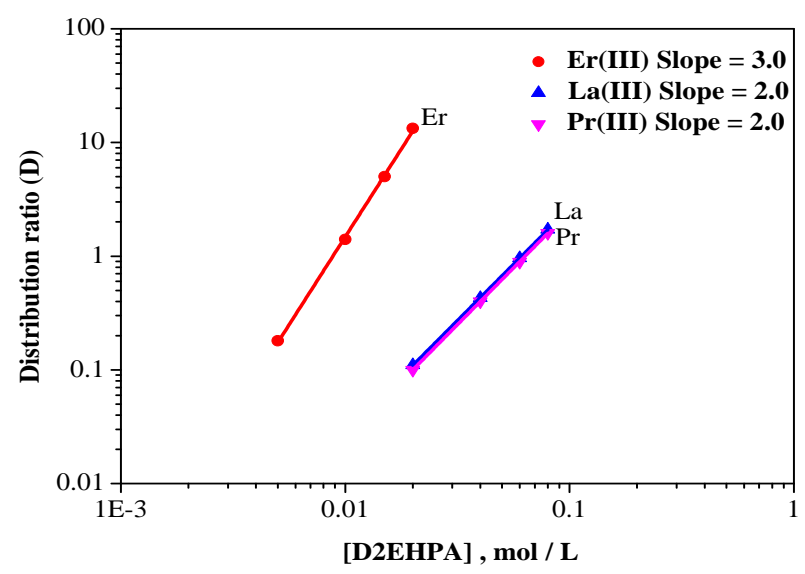

Figure (7): The log-log linear relationships between the extractant concentrations with the corresponding distribution ratios in the extraction of $\operatorname{Er}($ III), $\mathrm{La}($ III) and $\operatorname{Pr}$ (III) from $1.0 \mathrm{~mol} / \mathrm{L}$ citric acid solution at $\mathrm{pH}=4.0, \mathrm{O}: \mathrm{A}$ $=1$ and $25^{\circ} \mathrm{C}$.

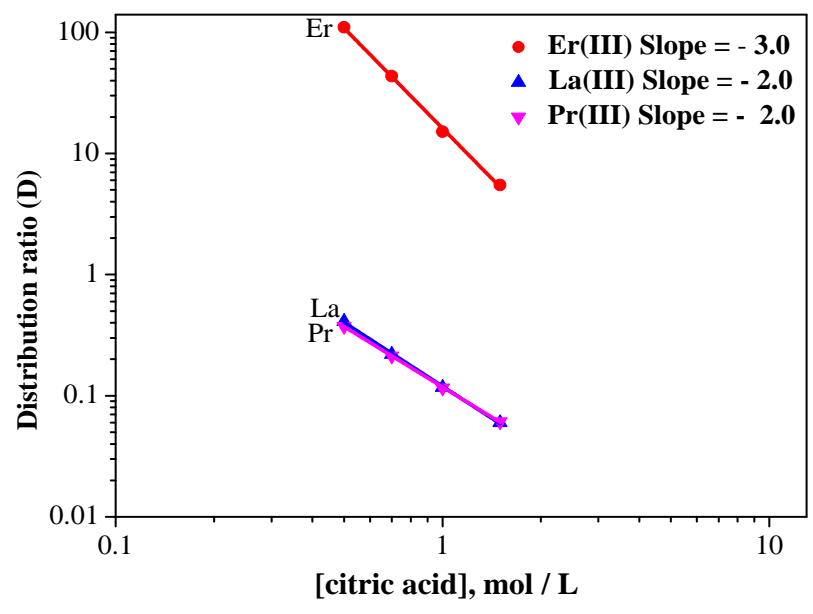

Figure (8): The log-log relationship between the citric acid concentrations and the corresponding distribution ratios in the extraction of $\mathrm{Er}$ (III), $\mathrm{La}$ (III) and $\operatorname{Pr}$ (III) using 0.02 mol/L D2EHPA in kerosene at $\mathrm{pH}=4, \mathrm{O}: \mathrm{A}=1$ and $25^{\circ} \mathrm{C}$.

Different values of the conditional extraction constant calculated based on equation (7) at different D2EHPA and citric acid concentrations are given in tables (1 and 2). The mean values of $\mathrm{K}_{\mathrm{C} \text {.ex }}$ for $\mathrm{La}(\mathrm{III}), \operatorname{Pr}(\mathrm{III})$ and $\mathrm{Er}$ (III) extraction given in the tables by D2EHPA were found to equal $2.8 \pm 0.14 \times 10^{2}, \quad 2.7 \pm 0.23 \times 10^{2}$ and $1.72 \pm 0.32 \times 10^{6}$, respectively. 
Table (1): Conditional extraction constants $\mathrm{K}_{\mathrm{C} . \mathrm{ex}}$ for $\operatorname{Er}(\mathrm{III})$, $\mathrm{La}(\mathrm{III})$ and $\operatorname{Pr}$ (III) extraction by different concentrations of D2EHPA in kerosene*.

\begin{tabular}{cccc}
\hline & \multicolumn{3}{c}{$\mathrm{K}_{\text {C.ex }}$} \\
\cline { 2 - 4 } & $\mathrm{La}(\mathrm{III}) \times 10^{2}$ & $\operatorname{Pr}(\mathrm{III}) \times 10^{2}$ & $\operatorname{Er}(\mathrm{III}) \times 10^{6}$ \\
\hline 0.005 & -- & -- & 1.44 \\
0.01 & -- & -- & 1.40 \\
0.015 & -- & -- & 1.48 \\
0.02 & 2.75 & 2.50 & 1.66 \\
0.04 & 2.69 & 2.50 & -- \\
0.06 & 2.67 & 2.47 & -- \\
0.08 & 2.69 & 2.50 & -- \\
$\mathrm{K}_{\text {ex }}$ (average) & $2.70 \pm 0.03$ & $2.49 \pm 0.02$ & $1.49 \pm 0.12$ \\
\hline
\end{tabular}

*1.0 mol/L citric acid at $\mathrm{pH}=4.0$

Table (2): Conditional extraction constants $K_{\text {C.ex }}$ for $\operatorname{Er}($ III), La(III) and Pr(III) extraction by D2EHPA in kerosene at different citric acid concentrations*

\begin{tabular}{cccc}
\hline \multirow{2}{*}{ [citric acid], $\mathbf{~ m o l} / \mathbf{L}$} & \multicolumn{3}{c}{$\mathrm{K}_{\text {C.ex }}$} \\
\cline { 2 - 4 } & $\mathrm{La}(\mathrm{III}) \times 10^{2}$ & $\operatorname{Pr}(\mathrm{III}) \times 10^{2}$ & $\operatorname{Er}(\mathrm{III}) \times 10^{6}$ \\
\hline 0.50 & 2.57 & 2.34 & 1.72 \\
0.70 & 2.70 & 2.61 & 1.86 \\
1.0 & 2.93 & 2.90 & 1.89 \\
1.5 & 3.38 & 3.43 & 2.32 \\
$\mathrm{~K}_{\text {ex }}($ average $)$ & $2.89 \pm 0.36$ & $2.82 \pm 0.47$ & $1.95 \pm 0.26$ \\
\hline
\end{tabular}

$* 0.02 \mathrm{~mol} / \mathrm{L} \mathrm{D} 2 \mathrm{EHPA}$ at $\mathrm{pH}=4.0$

The distribution ratios for $\mathrm{La}(\mathrm{III}), \operatorname{Pr}(\mathrm{III})$ and Er(III) are calculated from equation (8) at different D2EHPA and citric acid concentrations. The calculated and the corresponding experimental values at different D2EHPA and citric acid concentrations are presented in tables (3 and 4), respectively. There is a great agreement between the experimental and calculated values which supports the proposed extraction mechanism.

\section{Effect of Temperature}

The effect of temperature on the extraction of 0.5 $\mathrm{g} / \mathrm{L}$ of $\mathrm{Er}(\mathrm{III}), \mathrm{La}(\mathrm{III})$ and $\operatorname{Pr}(\mathrm{III})$ from $1.0 \mathrm{~mol} / \mathrm{L}$ citric acid solution by D2EHPA was studied in the temperature range $15-65^{\circ} \mathrm{C}$. The obtained results show that by increasing temperature, the extraction percent of the three metal ions decreased, Figure(10). The plot of $\ln K_{\text {C.ex }}$ versus $1 / T$ resulted in straight lines for different metal ions, Figure(11). Based on this linear relations, the thermodynamic parameters were calculated from the following relations [38].

$$
\begin{aligned}
& \ln \mathrm{k}_{\mathrm{C} . \mathrm{ex}}=\frac{-\Delta \mathrm{H}}{\mathrm{RT}}+\mathrm{C} \\
& \Delta \mathrm{G}^{\mathrm{o}}=-\mathrm{RT} \ln \mathrm{K}_{\mathrm{ex}} \\
& \Delta S^{o}=\frac{\Delta H^{o}-\Delta G^{o}}{\mathrm{~T}}
\end{aligned}
$$


Table (3): The calculated and experimental values of the distribution ratio for $\operatorname{Er}($ III), $\operatorname{La}($ III) and $\operatorname{Pr}$ (III) at different D2EHPA concentrations.

\begin{tabular}{|c|c|c|c|c|c|c|}
\hline \multirow{2}{*}{ [D2EHPA], mol /L } & \multicolumn{2}{|c|}{$\mathrm{La}(\mathrm{III})$} & \multicolumn{2}{|c|}{$\operatorname{Pr}(\mathrm{III})$} & \multicolumn{2}{|c|}{$\operatorname{Er}($ III) } \\
\hline & $\mathrm{D}_{\text {experimented }}$ & $\mathrm{D}_{\text {calculated }}$ & $\mathrm{D}_{\text {experimented }}$ & $\mathrm{D}_{\text {calculated }}$ & $\mathrm{D}_{\text {experimented }}$ & $\mathrm{D}_{\text {calculated }}$ \\
\hline 0.005 & -- & -- & -- & -- & 0.18 & 0.215 \\
\hline 0.01 & -- & -- & -- & -- & 1.40 & 1.72 \\
\hline 0.015 & -- & -- & -- & -- & 5.01 & 5.81 \\
\hline 0.02 & 0.11 & 0.112 & 0.10 & 0.11 & 13.3 & 13.76 \\
\hline 0.04 & 0.43 & 0.45 & 0.40 & 0.43 & -- & -- \\
\hline 0.06 & 0.96 & 1.01 & 0.89 & 0.97 & -- & -- \\
\hline 0.08 & 1.72 & 1.79 & 1.60 & 1.73 & -- & -- \\
\hline
\end{tabular}

Table (4): The calculated and experimental values of the distribution ratio for $\operatorname{Er}($ III), La(III) and $\operatorname{Pr}($ III) at different citric acid concentrations

\begin{tabular}{ccccccc}
\hline \multirow{2}{*}{ [Citric acid], mol/ L } & \multicolumn{2}{c}{$\mathrm{La}(\mathrm{III})$} & \multicolumn{2}{c}{$\operatorname{Pr}(\mathrm{III})$} & $\mathrm{Er}$ (III) \\
\cline { 2 - 7 } 0.50 & $\mathrm{D}_{\text {experimented }}$ & $\mathrm{D}_{\text {calculated }}$ & $\mathrm{D}_{\text {experimented }}$ & $\mathrm{D}_{\text {calculated }}$ & $\mathrm{D}_{\text {experimented }}$ & $\mathrm{D}_{\text {calculated }}$ \\
\cline { 2 - 7 } 0.411 & 0.45 & 0.374 & 0.43 & 110.11 & 110.08 \\
0.70 & 0.22 & 0.23 & 0.213 & 0.22 & 43.44 & 40.12 \\
1.0 & 0.117 & 0.112 & 0.116 & 0.11 & 15.33 & 13.76 \\
1.50 & 0.06 & 0.05 & 0.061 & 0.05 & 5.49 & 4.08 \\
\hline
\end{tabular}

Where, $\Delta \mathrm{H}^{0}, \Delta \mathrm{G}^{0}$ and $\Delta \mathrm{S}^{0}$ are standard enthalpy change, the free energy change, and entropy change, respectively. $\mathrm{R}$ is the universal gas constant $\left(8.314 \mathrm{~J} \mathrm{~mole}^{-1} \mathrm{~K}^{-1}\right), \mathrm{C}$ is a constant and $\mathrm{T}$ is the absolute temperature.

From equation (9) and the slope obtained from Figure(10), the standard enthalpy variation $\left(\Delta \mathrm{H}^{\circ}\right)$ is obtained. The free energy change $\left(\Delta G^{\circ}\right)$ is obtained by applying equation (10) at standard state, $298 \mathrm{~K}$, and the entropy variation $\left(\Delta \mathrm{S}^{\circ}\right)$ is obtained using equation (11); the calculated values are given in Table (5).

The tabuated data showed that the extraction of $\mathrm{Er}(\mathrm{III}), \mathrm{La}$ (III) and $\mathrm{Pr}(\mathrm{III})$ is exothermic as indicated by the negative values of $\Delta \mathrm{H}^{\circ}$. The reaction of the three metals with D2EHPA is spontaneous in nature as shown by the negative sign of $\Delta \mathrm{G}^{\mathrm{o}}$ values while the positive values of $\Delta \mathrm{S}^{\mathrm{o}}$ for the three elements show an increase in the randomness of the system during the formation of the extracted species.

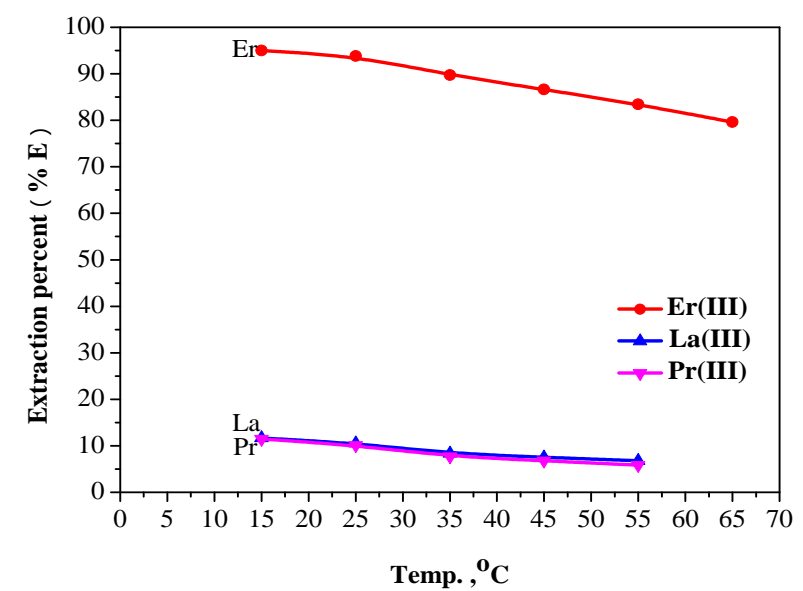

Figure (10): Effect of temperature on the extraction of Er(III), La(III) and $\operatorname{Pr}($ III) with $0.02 \mathrm{~mol} / \mathrm{L}$ D2EHPA in kerosene from $1.0 \mathrm{~mol} / \mathrm{L}$ citric acid Solution at $\mathrm{pH}=4$ and $\mathbf{O}: \mathbf{A}=\mathbf{1}$. 
Table (5): Thermodynamic parameters of the extraction of $\operatorname{Er}(\mathrm{III}), \mathrm{La}(\mathrm{III})$ and $\operatorname{Pr}(\mathrm{III})$. from $1.0 \mathrm{~mol} / \mathrm{L}$ citric acid solution at $\mathrm{pH} 4.0$ by $0.02 \mathrm{~mol} / \mathrm{L}$ D2EHPA in kerosene at $\mathrm{O}: \mathrm{A}=\mathbf{1}$.

\begin{tabular}{lccc}
\hline Thermodynamic parameter & $\mathrm{Er}(\mathrm{III})$ & $\mathrm{La}(\mathrm{III})$ & $\operatorname{Pr}(\mathrm{III})$ \\
\hline $\begin{array}{l}\text { Enthalpy change }\left(\Delta \mathrm{H}^{\mathrm{o}}\right), \mathrm{kJ} \\
\text { mole }\end{array}$ & -9.72 & -4.36 & -5.31 \\
$\begin{array}{l}\text { Free energy change }\left(\Delta \mathrm{G}^{\mathrm{o}}\right), \\
\mathrm{kJ} \text { mole }\end{array}$ & -15.56 & -6.12 & -6.07 \\
$\begin{array}{l}\text { Entropy change }\left(\Delta \mathrm{S}^{\mathrm{o}}\right), \mathrm{J} \\
\text { mole }^{-1} \mathrm{~K}^{-1}\end{array}$ & 19.60 & 5.91 & 2.55 \\
\hline
\end{tabular}

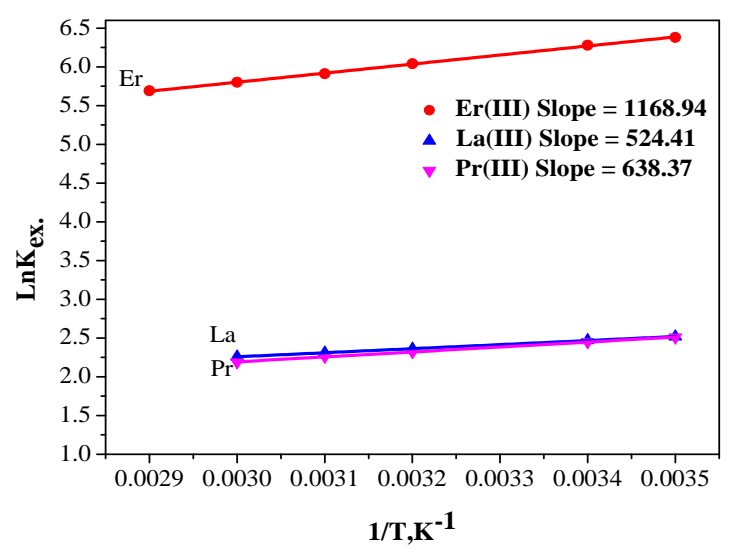

Figure. (11): Relation between $\left(\operatorname{lnK}_{\mathrm{C} . \mathrm{ex}}\right)$ and $(1 / \mathrm{T})$ for the extraction of $\operatorname{Er}(\mathrm{III}), \mathrm{La}(\mathrm{III})$ and $\operatorname{Pr}(\mathrm{III})$ with D2EHPA in kerosene from $1.0 \mathrm{~mol} / \mathrm{L}$ citric acid solution.

\section{Separation Feasibility}

The separation between $\operatorname{Er}$ (III) and $\mathrm{La}$ (III) is represented by the separation factor (SF) which is given by the ratio of their distribution ratios at equilibrium as follows,

$$
\mathrm{SF}_{(\mathrm{Er} / \mathrm{La})}=\frac{\mathrm{D}_{\mathrm{Er}}}{\mathrm{D}_{\mathrm{La}}}
$$

Where, $\mathrm{D}_{\mathrm{Er}}$ and $\mathrm{D}_{\mathrm{La}}$ are the distribution ratios of $\mathrm{Er}(\mathrm{III})$ and $\mathrm{La}$ (III), respectively.

From equations 8 the $\mathrm{D}$ of $\mathrm{Er}$ (III) and $\mathrm{La}(\mathrm{III})$ are given as:

$\mathrm{D}_{\mathrm{La}}=\frac{\mathrm{K}_{\mathrm{C} . \mathrm{La}}\left[(\mathrm{HA})_{2}\right]^{2}}{\left[\mathrm{H}_{3} \mathrm{Cit}\right]^{2}}$

and

$$
\mathrm{D}_{\mathrm{Er}}=\frac{\mathrm{K}_{\mathrm{C.Er}}\left[(\mathrm{HA})_{2}\right]^{3}}{\left[\mathrm{H}_{3} \mathrm{Cit}\right]^{3}}
$$

Substituting from equations (14 and 13) in equation (12) gives:

$$
\mathrm{SF}_{(\mathrm{Er} / \mathrm{La})}=\frac{\mathrm{K}_{\mathrm{C} . \mathrm{Er}}\left[(\mathrm{HA})_{2}\right]}{\mathrm{K}_{\mathrm{C} . \mathrm{La}}\left[\mathrm{H}_{3} \mathrm{Cit}\right]}
$$

Substituting with the mean $\mathrm{K}_{\mathrm{C} . \mathrm{ex}}$ values obtained for Er and La :

$$
\begin{gathered}
\mathrm{SF}_{(\mathrm{Er} / \mathrm{La})}=\frac{1.72 \times 10^{6}\left[(\mathrm{HA})_{2}\right]}{2.8 \times 10^{2}\left[\mathrm{H}_{3} \mathrm{Cit}\right]} \\
\mathrm{SF}_{(\mathrm{Er} / \mathrm{La})}=6.14 \times 10^{3} \frac{\left[(\mathrm{HA})_{2}\right]}{\left[\mathrm{H}_{3} \mathrm{Cit}\right]}
\end{gathered}
$$

Using similar mathematical treatment, the separation factor between $\operatorname{Er}(\mathrm{IIII})$ and $\operatorname{Pr}(\mathrm{III})$ can be calculated from the relations:

$$
\mathrm{SF}_{(\mathrm{Er} / \mathrm{Pr})}=6.37 \times 10^{3} \frac{\left[(\mathrm{HA})_{2}\right]}{\left[\mathrm{H}_{3} \mathrm{Cit}\right]}
$$

The $\mathrm{SF}_{(\mathrm{Er} / \mathrm{La} \text { or Pr) }}$ calculated from equations (17 and 18) depend on the extractant concentration and acid concentration. The plot of the SF against D2EHPA concentration at $1.0 \mathrm{~mol} / \mathrm{L}$ citric acid, Figure(12), indicates that as the D2EHPA concentration increases, the separation factor between $\mathrm{Er}$ (III) and $\mathrm{La}$ (III), or $\operatorname{Pr}(\mathrm{III})$ increases.

Furthermore, from the plot of the relation between the SF and different citric acid at $\mathrm{pH} 4.0$ and D2EHPA concentrations of $0.02 \mathrm{~mol} / \mathrm{L}$, Figure(13), it is clear that as the citric acid concentration increases, the separation factor between $\mathrm{Er}$ (III) and La (III) or $\operatorname{Pr}(\mathrm{III})$ decreases.

The SF values given by the ratio of their extraction constants and listed in Table 6 show that the separation of $\mathrm{Er}$ (III) from $\operatorname{Pr}(\mathrm{III})$ or $\mathrm{La}(\mathrm{III})$ is in the order: $\mathrm{S}_{\mathrm{Er} r \mathrm{Pr}}>\mathrm{S}_{\mathrm{Er} / \mathrm{La}}$.

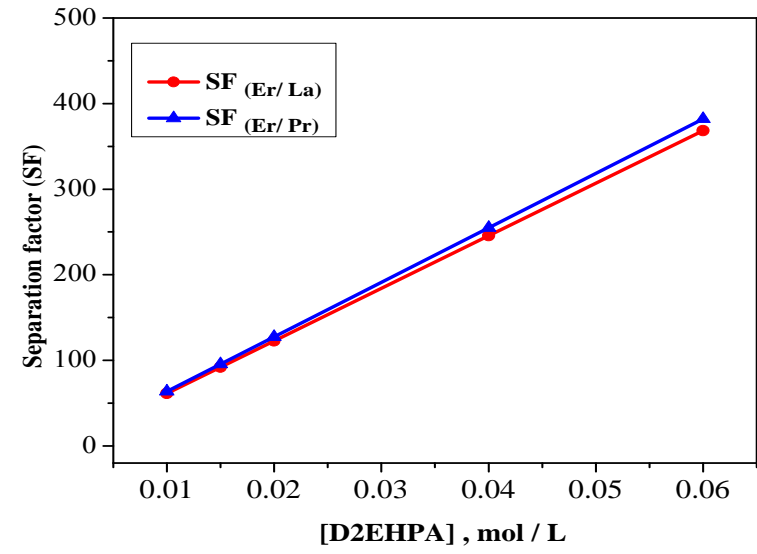

Figure (12): Effect of D2EHPA concentration on the separation factor $\left(\mathrm{SF}_{(\mathrm{Er} / \mathrm{La} \text { or } \mathrm{Pr})}\right)$ aqueous phase, $1.0 \mathrm{~mol} / \mathrm{L}$ citric acid solution at $\mathrm{pH}$ 4.0. 


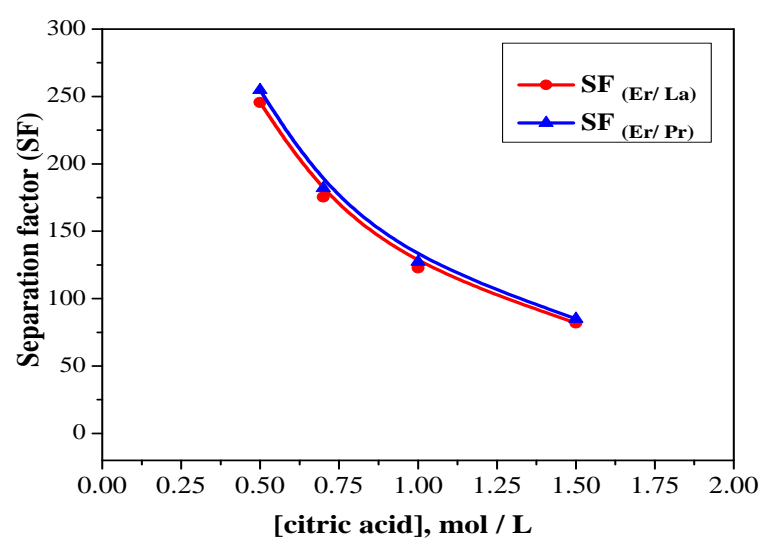

Figure (13): Effect of citric acid concentration at $\mathrm{pH} 4.0$ on the separation factor $\left(\mathrm{SF}_{(\mathrm{Er} / \mathrm{La}}\right.$ or $\left.\mathrm{Pr}\right)$ by $0.02 \mathrm{~mol} / \mathrm{L}$ D2EHPA organic phase.

Table (6): Separation of $\operatorname{Er}($ III), La (III) and $\operatorname{Pr}($ III) extracted from $1.0 \mathrm{~mol} / \mathrm{L}$ citric acid solution using 0.02 mol/L D2EHPA in kerosene.

\begin{tabular}{ccc}
$\mathrm{K}_{\mathrm{C} . \mathrm{ex}}(\mathrm{Er})$ & $\mathrm{K}_{\mathrm{C} . \mathrm{ex}}(\mathrm{La})$ & $\mathrm{K}_{\mathrm{C} . \mathrm{ex}}(\mathrm{Pr})$ \\
\hline $1.72 \times 10^{6}$ & $2.8 \times 10^{2}$ & $2.7 \times 10^{2}$ \\
$\mathrm{~S}_{\mathrm{Er} / \mathrm{La}}$ & $\mathrm{S}_{\mathrm{Er} / \mathrm{Pr}}$ & $\mathrm{S}_{\mathrm{La} / \mathrm{Pr}}$ \\
122.8 & 127.4 & 1.04 \\
\hline
\end{tabular}

Table (7): Effect of D2EHPA concentration on the separation between $\operatorname{Er}$ (III), La(III) and Pr(III).

\begin{tabular}{cccc}
\hline \multirow{2}{*}{ [D2EHPA], mol/ L } & \multicolumn{4}{c}{ Separation factors } \\
\cline { 2 - 4 } 0.02 & Er/La & Er/Pr & La/Pr \\
\cline { 2 - 4 } 0.04 & 120.91 & 133.0 & 1.1 \\
0.06 & -- & -- & 1.08 \\
0.08 & -- & -- & 1.09 \\
\hline
\end{tabular}

Based on the separation factors given in tables 6 and 7 it is clear that separation of Er(III) from both $\mathrm{La}$ (III) and $\mathrm{Pr}$ (III) can be achieved satisfactorly by extraction of Er(III) using $0.02 \mathrm{~mol} / \mathrm{L}$ D2EHPA from $1.0 \mathrm{~mol} / \mathrm{L}$ citric acid where by separation of $\mathrm{La}$ (III) from $\operatorname{Pr}$ (III) is difficult to be achieved under the same conditions.

\section{Conclusion}

From the experimental results the following points were concluded:
The extraction of $\operatorname{Er}(\mathrm{III}), \mathrm{La}$ (III) and $\operatorname{Pr}(\mathrm{III})$ from 1.0 citric acid by D2EHPA was found to slightly increased by the increase of $\mathrm{pH}$ values from $1.0-$ 4.0. The extraction of these elements were found to increase by increasing D2EHPA concentration and decrease by the increase of citric acid concentration at $\mathrm{pH}$ 4.0. Therefore,

1- The experimental results in terms of D2EHPA concentration in the organic phase and $\operatorname{Ln}(\mathrm{III})$ ions in 1.0 citric acid at $\mathrm{pH} 4.0$ in the aqueous phase may give the reaction:

$\mathrm{Ln}\left(\mathrm{H}_{2} \mathrm{Cit}\right)_{3}+n(\mathrm{HA})_{2 \text { org }} \leftrightarrow\left[\mathrm{Ln}\left(\mathrm{H}_{2} \mathrm{Cit}\right)_{3-n} . n \mathrm{~A} \cdot(\mathrm{HA})_{2}\right]_{\text {org }}+n \mathrm{H}_{3} \mathrm{Cit}$

2- The mean species in the organic phase are the following, $\quad\left[\mathrm{La}\left(\mathrm{H}_{2} \mathrm{Cit}\right) .2 \mathrm{~A}(\mathrm{HA})\right], \quad\left[\mathrm{Pr}\left(\mathrm{H}_{2} \mathrm{Cit}\right)\right.$. 2A(HA)] and [Er.3A(HA)], where the cationic complexes of $\left[\mathrm{La}\left(\mathrm{H}_{2} \mathrm{Cit}\right)\right]^{2+}$ and $\left[\mathrm{Pr}\left(\mathrm{H}_{2} \mathrm{Cit}\right)\right]^{2+}$ are extracted, while in the case of erpium the free cationic species of $\mathrm{Er}^{3+}$ is extracted by D2EHPA.

3- Conditional extraction constant for Er (III), $\mathrm{La}$ (III) and $\mathrm{Pr}$ (III) extraction by D2EHPA from 1.0 citric acid at $\mathrm{pH} 4.0$ solution was found to follow the order $1.72 \pm 0.32 \times 10^{6}>>$ $2.8 \pm 0.14 \times 10^{2} \geq 2.7 \pm 0.23 \times 10^{2}$

4- Separation feasibility in terms of the conditional extraction constant indicated that the separation factor of $\mathrm{Er}$ (III) from $\mathrm{La}$ (III) and $\operatorname{Pr}(\mathrm{III})$ increases by the increase of D2EHPA concentration at $\mathrm{pH} \quad 4.0$ and decreases by the increase of citric acid concentration.

\section{Acknowledgements}

This research is funded by the Egyptian Atomic Energy Authority and did not receive any specific grant from funding agencies in the public, commercial, or not-forprofit sectors.

\section{References}

1- I.McGill, "In Ullmann's Encyclopedia of Industrial Chemistry". Gerhartz, W, Yamamoto Y S, Campbell F T, Pfefferkon R, Rounsaville J F, Edited by Weinheim F R G, Deerfield Beach F L. USA: VCH Publisher, Vol A22, 1993.

2- S. Vijayan, A.J. Melnyk, R.D. Singh, K. Nuttall, "Rare Earths: their mining, processing and growing industrial usage". Min. Eng. Vol. 41, PP. 13- 18, 1989.

3- M.F. Bari, B. Saad, I.A. Rahman, M.I. Saleh, "Extraction mechanism of $\mathrm{Gd}^{3+}$ by BTMPPA". $J$. Alloy. Compd. Vol. 436, PP. 187- 194, 2007.

4- D.Li, 'Development course of separating rere earths with acid phosphorus extractants : A critical 
review", Journal of Rare Earths, //doi.org/j.jre.2018.07.016 .

5- N.E. El-Hefny, Y.A. El-Nadi, J.A. Daoud, "Equilibrium and mechanism of samarium extraction from chloride medium using sodium salt of CYANEX 272". Sep. Purif. Technol. Vol. 75, PP. 310-315, 2010.

6- Y.A. El-Nadi, "Effect of diluents on the extraction of praseodymium andsamarium by Cyanex 923 from acidic nitrate medium". J. Rare. Earth. Vol. 28, PP. 215-220, 2010.

7- S. Radhika, B.N. Kumar, M.L. Kantam, B.R. Reddy, "Liquid-liquid extraction and separation possibilities of heavy and light rare-earths from phosphoric acid solutions with acidic organophosphorus reagents". Sep. Purif. Technol. Vol. 75, PP. 295-302, 2010.

8- S. Radhika, B.N. Kumar, M.L. Kantam, B.R. Reddy, "Solvent extraction and separation of rareearths from phosphoric acid solutions with TOPS 99". Hydrometallurgy .Vol. 110, PP. 50-55, 2011.

9- X. Sun, S. Meng, D. Li, "Studies on the synergistic extraction of rare earths with a combination of 2ethylhexylphosphonic acid mono-2-ethylhexyl ester and trialkylphosphine oxide". J. Chem. Technol. Biotechnol. Vol. 81, PP. 755-760, 2006.

10- Z. Zhang, H. Li, F. Guo, S. Meng, D. Li, "Synergistic extraction and recovery of Cerium(IV) and Fluorine from sulfuric solutions with Cyanex 923 and di-2-ethylhexyl phosphoric acid". Sep. Purif. Technol. Vol. 63, PP. 348-352, 2008.

11- J.C. Braley, T.S. Grimes, K.L. Nash, "Alternatives to HDEHP and DTPA for Simplified TALSPEAK Separations". Ind. Eng. Chem. Res. Vol. 51, PP. 629-638, 2012.

12- G.J. Lumetta, A.V. Gelis, J.C. Braley, J.C. Carter, G.W. Pittman, M.G. Warner, G.F. Vandegrift, "The TRUSPEAK concept: combining CMPO and HDEHP for separating trivalent lanthanides from the transuranic elements". Solvent Extr. Ion Exc. Vol. 31, PP. 223-236, 2013.

13- D. Beltrami, G. Cote, H. Mokhtari, B. Courtaud, A. Chagnes, "Modeling of the extraction of uranium(VI) from concentrated phosphoric acid by synergistic mixtures of bis-(2-ethylhexyl)phosphoric acid and tri-n-octylphosphine oxide". Hydrometallurgy. Vol. 129-130, PP. 118-125, 2012.

14- I.C. Basualto, F.I. Valenzuela, I. Molina, J.P. Munoz, E.Fuentes, J.Sapag, "Study of the solvent extraction of the lighter lanthanide metal ions by means of organophosphorus extractants". J. Chil. Chem. Soc. Vol. 58, PP. 1785-1789, 2013.

15- S.M. Deshpande, S.L. Mishra, R.B. Gajankush, N.V. Thakur, K.S. Koppiker, "Recovery of high purity $\mathrm{Y}_{2} \mathrm{O}_{3}$ by solvent extraction route using organophosphorus extractants". Miner. Process. Extr. Metall. Rev. Vol. 10, PP. 267-273, 1992.
16- A. Geist, W. Nitsch, J. Kim, "On the kinetics of rare-earth extraction into D2EHPA". Chem. Eng. Sci. Vol. 54, PP. 1903-1907, 1999.

17- F. Xie, T.A. Zhang, D. Dreisinger, F. Doyle, “A critical review on solvent extraction of rare earths from aqueous solutions". Miner. Eng. Vol. 56, PP. 10-28, 2014.

18- Y.G. Wang, Y. Xiong, S.L. Meng, D.Q. Li, "Separation of yttrium from heavy lanthanide by CA-100 using the complexing agent". Talanta. Vol. 63, PP. 239-243, 2004.

19- X. Sun, Y. Wang, D. Li, "Selective separation of yttrium by CA-100 in the presence of a complexing agent". J. Alloys Compd.Vol. 408-412, PP. 9991002, 2006.

20- S. Nishihama, T. Hirai, I. Komasawa, "Selective Extraction of $\mathrm{Y}$ from a $\mathrm{Ho} / \mathrm{Y} / \mathrm{Er}$ Mixture by Liquid-Liquid Extraction in the Presence of a Water-Soluble Complexing Agent". Ind. Eng. Chem. Res. Vol. 39, PP. 3907-3911, 2000.

21- S. Nishihama, T. Hirai, I. Komasawa, "Review of Advanced Liquid-Liquid Extraction Systems for the Separation of Metal Ions by a Combination of Conversion of the Metal Species with Chemical Reaction". Ind. Eng. Chem. Res. Vol. 40, PP. 30853091, 2001

22- S. Nishihama, T. Hirai, I. Komasawa, "Advanced liquid-liquid extraction systems for the separation of rare earth ions by combination of conversion of the metal species with chemical reaction". J. Solid State Chem. Vol. 171, PP. 101-108, 2003.

23- S.N. Bhattacharyya, K.M. Ganguly, "The effect of complexing agents on the extraction of lanthanides by di (2-ethyl hexyl) phosphoric acid". Hydrometallurgy. Vol. 32, PP. 201-208, 1993.

24- H. Chang, M. Li, Z. Liu, Y. Hu, F. Zhang, "Study on separation of rare earth elements in complex system". J. Rare Earth. Vol. 28, PP. 116-119, 2010.

25- P.K. Zalupski, K.L. Nash, L.R. Martin, "Thermodynamic features of the complexation of neodymium(III) and americium(III) by lactate in trifluoromethane sulfonate media". J. Solution Chem. Vol. 39, PP. 1213-1229, 2010.

26- H. Matsuyama, A. Azis, M. Fujita, M. Teramoto, "Enhancement in extraction rates by addition of organic acids to aqueous phase in solvent extraction of rare earth metals in presence of diethylenetriamine-pentaacetic acid". J. Chem. Eng. Jpn. Vol. 29, PP. 126-133, 1996.

27- W. Weaver, F.A. Kappelmann, "Preferential extraction of lanthanides over trivalent actinides by monoacidic organophosphates from carboxylic acids and from mixtures of carboxylic and aminopolyacetic acids". J Inorg Nucl Chem.Vol. 30, PP. 263-272, 1968.

28- T. Ohnukia, N. Kozaia, F. Sakamotoa, Y. Suzukia, T. Yoshida, "Biological Change of Chemical States 
of Actinides and Lanthanides -Effects of Organic Acids" Energy Procedia. Vol. 39, PP. 175-182, 2013.

29- A.S. Suneesh, Jammu Ravi, K.A. Venkatesan, M. P. Antony, T.G. Srinivasan, P.R. Vasudeva Rao,"Lanthanide-actinide separation by bis-2ethylhexylphosphoric acid from citric acid-nitric acid medium". J Radioanal Nucl Chem . Vol. 285, PP. 653-658, 2010.

30- S. Yin, W. Wu, X. Bian, F. Zhang, "Effect of complexing agent lactic acid on the extraction and separation of $\operatorname{Pr}(\mathrm{III}) / \mathrm{Ce}(\mathrm{III})$ with di-(2-ethylhexyl) phosphoric acid" Hydrometallurgy. Vol. 133, PP. 131-132, 2013.

31- S. Yin, W. Wu, X. Bian, Y. Luo, F. Zhang, "Solvent extraction of $\mathrm{La}(\mathrm{III})$ from chloride medium in the presence of two water soluble complexing agents with di-(2-ethylhexyl) phosphoric acid" Ind. Eng. Chem. Res. Vol. 52, PP. 8558-8564, 2013.

32- S.H. Yin, S.W. Li, W.Y. Wu, X. Bian, J.H. Peng, L.B. Zhang, "Extraction and separation of $\mathrm{Ce}(\mathrm{III})$ and $\operatorname{Pr}(\mathrm{III})$ in the system containing two complexing agents with di-(2-ethylhexyl) phosphoric acid". RSC Adv. Vol. 4, PP. 5999760001, 2014.

33- E.M. Abu Elgoud, "Leaching and Separation of Certain Lanthanides from Selected Matrix". MSc, Faculty of Science, Al-Azhar University, Egypt, 2015.

34- Z. Marczenko, "Spectrophotometric Determination of Elements"; Ellis Harwood Ltd: Poland, 1976.

35- D. R. Lide, "Handbook of Chemistry and Physics", 84 ${ }^{\text {th }}$ Edition, 2004.

36- www.kemi.kth.se/medusa.

37- F.B. Charles, E.M. Rabert, "The hydrolysis of Cations" Wiley-Interscience Publication, John Wiley \& Sons Inc, 1976.

38- J.H. Van't Hoff, "The role of osmotic pressure in the analogy between solutions and gases". J. Membr. Sci. Vol. 100, PP. 39-44, 1995. 